
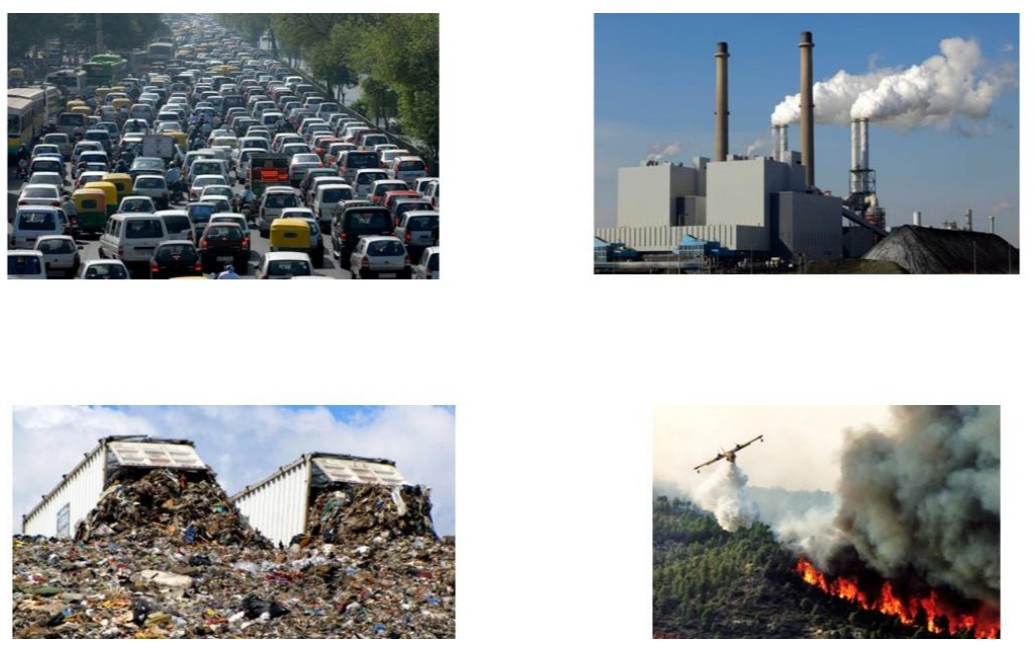

\title{
What Impact has air pollution on health of human beings and environment? Is there any relation between covid-19 \& air pollution?
}

DR PIYUSH KUMAR ${ }^{1}$

1 B. R. Ambedkar Bihar University

Funding: The author(s) received no specific funding for this work.

Potential competing interests: The author(s) declared that no potential competing interests exist.

\section{Abstract}

Almost all the countries around the world are experiencing high levels of air pollution. How does pollution impact our body in times of COVID-19? Air pollution and related climatic-environmental changes is one of the prime concern and biggest challenge globally in $21^{\text {st }}$ century faced by most of the nations. The global impact of this public health problem can be assessed and understood from the data of morbidity and mortality as well as DALY (disability adjusted life years) \& QALY (quality adjusted life years), YLL (years of life lost) measurements. Today global air is having several varieties and types of air pollutants which are taking lives of people on daily basis and the death count may be more as compared to covid-19 deaths. The finest and smallest particulate matters present in air as byproducts of several human and industry related activities are able to infiltrate the respiratory system through inhalation while breathing, leading to respiratory and cardiovascular system(CVS) diseases, reproductive and central nervous system(CNS) diseases and malfunctioning as well as various carcinoma. Ozone $\left(\mathrm{O}_{3}\right)$ protects us from harmful effects of UV (ultra violet) radiations which can cause cancers, skin diseases as well as mutations etc but at the same time it is harmful when in high concentration at ground level, 
affecting the respiratory and cardiovascular system. Added to this other pollutants present in air such as nitrogen oxide( $\mathrm{NO})$, sulfur dioxide $\left(\mathrm{SO}_{2}\right)$, Volatile Organic Compounds (VOCs), dioxins, and polycyclic aromatic hydrocarbons (PAHs) are all important air pollutants which are known to be harmful to human beings. Carbon monoxide $(\mathrm{CO})$ can bind with haemoglobin $(\mathrm{Hb})$ very tightly (not allowing oxygen to be released at tissue level causing tissue hypoxia) forming carboxy-haemoglobin which can cause poisoning when breathed in at high levels. Heavy metals for example lead $(\mathrm{Pb})$ can lead to direct poisoning (plumbinism or saturnism) or chronic intoxication can lead to a variety of CNS, GIT(gastrointestinal tract), and reproductive system diseases, depending on the exposure. Air pollution usually causes respiratory problems such as Chronic Obstructive Pulmonary Disease (COPD), asthma, bronchiolitis, lung cancer, cardiovascular events, central nervous system dysfunctions, and cutaneous diseases. Added to this, the climate change resulting from environmental pollution affects the geographical distribution of many infectious diseases like natural disasters as well as affects social and environmental determinants of health. The only way to tackle this problem is through public health awareness, strategies to reduce air pollution as well as environmental protection measures with a multidisciplinary Intersectoral approach by scientific experts of national and international organizations. The global leaders must address the emergence of this threat and propose sustainable and suitable solutions to deal this challenging issue.

Keywords: Covid-19, air pollution, environment, health, disease, policy, pollutant, public health,

\section{Dr Piyush Kumar ${ }^{1}$}

\section{ABSTRACT}

Almost all the countries around the world are experiencing high levels of air pollution. How does pollution impact our body in times of COVID-19? Air pollution and related climatic-environmental changes is one of the prime concern and biggest challenge globally in $21^{\text {st }}$ century faced by most of the nations. The global impact of this public health problem can be assessed and understood from the data of morbidity and mortality as well as DALY (disability adjusted life years) \& QALY (quality adjusted life years), YLL (years of life lost) measurements. Today global air is having several varieties and types of air pollutants which are taking lives of people on daily basis and the death count may be more as compared to covid-19 deaths. The finest and smallest particulate matters present in air as byproducts of several human and industry related activities are able to infiltrate the respiratory system through inhalation while breathing, leading to respiratory and cardiovascular system(CVS) diseases, reproductive and central nervous system(CNS) diseases and malfunctioning as well as various carcinoma. Ozone $\left(\mathrm{O}_{3}\right)$ protects us from harmful effects of UV (ultra violet) radiations which can cause cancers, skin diseases as well as mutations etc but at the same time it is harmful when in high concentration at ground level, affecting the respiratory and cardiovascular system. Added to this other pollutants present in air such as nitrogen oxide(NO), sulfur 
dioxide $\left(\mathrm{SO}_{2}\right)$, Volatile Organic Compounds (VOCs), dioxins, and polycyclic aromatic hydrocarbons (PAHs) are all important air pollutants which are known to be harmful to human beings. Carbon monoxide (CO) can bind with haemoglobin $(\mathrm{Hb})$ very tightly (not allowing oxygen to be released at tissue level causing tissue hypoxia) forming carboxy-haemoglobin which can cause poisoning when breathed in at high levels. Heavy metals for example lead $(\mathrm{Pb})$ can lead to direct poisoning (plumbinism or saturnism) or chronic intoxication can lead to a variety of CNS, GIT(gastrointestinal tract), and reproductive system diseases, depending on the exposure. Air pollution usually causes respiratory problems such as Chronic Obstructive Pulmonary Disease (COPD), asthma, bronchiolitis, lung cancer, cardiovascular events, central nervous system dysfunctions, and cutaneous diseases. Added to this, the climate change resulting from environmental pollution affects the geographical distribution of many infectious diseases like natural disasters as well as affects social and environmental determinants of health. The only way to tackle this problem is through public health awareness, strategies to reduce air pollution as well as environmental protection measures with a multidisciplinary Intersectoral approach by scientific experts of national and international organizations. The global leaders must address the emergence of this threat and propose sustainable and suitable solutions to deal this challenging issue.

Keywords: Covid-19, air pollution, environment, health, disease, policy, pollutant, public health,

\section{Background}

There are several studies done on ecological interactions and influence of environment on human beings. The environment consist of living and non living objects which interacts together as well as with human beings in various ways giving positive and negative impact on health and well being of humans. Simply air pollution can be defined as manipulation of air quality in natural or unnatural ways which can affect negatively well being of human and other species. The physical state of pollutants can be solid, liquid or gas. The growing populations globally have various activities which are causing pollution to increase day by day which must be stopped. The industrial revolutions have made human life easy and better but at the same time also produced pollution as unwanted outcome $\&$ is growing day by day.

Air pollution is one of the prime public health hazards globally as it accounts for about 7 million deaths per year. WHO data shows that $\mathbf{9}$ out of $\mathbf{1 0}$ people inhale air that exceeds WHO guideline limits containing high levels of pollutants, with low- and middle-income countries like India suffering from the highest exposures. WHO (world health organization) is supporting countries to address the problem and hazards of air pollution. The smog hanging over cities as well as smoke inside the home, air pollution poses a big threat to health and climate. The combined effects of ambient (outdoor) and household air pollution cause about seven million premature deaths every year, largely as a result of increased mortality from stroke, heart disease, chronic obstructive pulmonary diseases, lung cancers and acute respiratory infections (1).The Climate changes and global warming is affecting homeostasis of multiple ecosystems, giving rise to problems such as food safety issues, melting of glaciers and rise in sea level (recently Mumbai in India have been flooded due to massive cyclone tauktae), extinction of species as well as endangered, and damage to trees and houses. Exposure to air pollutants in short duration can give rise to 
COPD (Chronic Obstructive Pulmonary Disease),RTI (respiratory tract infections), difficulty in breathing, asthma, respiratory tract disease with high rates of hospitalization \& increased morbidity and mortality. Today several NCD have been found to be associated with air pollution. The ongoing covid-19 pandemic is hypothesized by several including myself to be transmissible to human through particulate matter $\left(\mathrm{PM}_{2.5}\right)$ acting as vehicle to be inhaled directly into lungs causing its rapid progression in highly polluted cities. The national capital of India is struggling with air pollution and Delhi has seen several fog and smog as well as emergency due to air pollution. Likewise globally London smog and others are giving globe a warning sign to control pollution. The finest particle and smallest one get entry easily to respiratory tract and from there transported and accumulated to various sites including CNS. The urban dwellers are affected more due to more sources of air pollution and less availability of trees acting as sink to several pollutants. The people living close to industrial areas are more prone to develop diseases. Household air pollution in India produced by burning biomass for cooking food etc is associated with major health risks in women and young children, who stay indoors for longer periods. COPD and lung cancer are mostly seen in women involved with cooking on biomass fuel, while acute lower respiratory disease is seen in young children less than 5 years of age. In low and middle income countries the situation is getting worse day by day due to unplanned development practices and policies as well as use of solid biomass for cooking. From the estimates of WHO (2016), 10 out of the 20 most populated cities in the world are in India. The findings are based on the concentrations of PM2.5 emissions, India was ranked the fifth most polluted country by WHO (2019), in which 21 among the top 30 polluted cities were in India. The Indian cities, on average, exceeded the WHO threshold by an alarming $\mathbf{5 0 0 \%}$ as per the findings of WHO. The London smog of 1952 is a big example of air pollution episodes in terms of its impact on science, public health, and government policies \& regulation. The association of health and air pollution during the episode was evident with strong rise in air pollution levels sulfur dioxide and smoke, reaching 1,500 mg/m3 was immediately followed by sharp increases in mortality and morbidity (2). In a study done by D W Dockery , C A Pope 3rd, X Xu, J D Spengler, J H Ware, M E Fay, B G Ferris Jr, F E Speizer, they found that Mortality rates were most strongly associated with cigarette smoking. After adjusting for smoking and other risk factors, they observed statistically significant and robust associations between air pollution and mortality. The adjusted mortality-rate ratio for the most polluted of the cities as compared with the least polluted was 1.26 (95 percent confidence interval, 1.08 to 1.47). Air pollution was positively associated with death from lung cancer and cardiopulmonary disease but not with death from other causes considered together. Mortality was most strongly associated with air pollution with fine particulates, including sulfates (3). World Health organization(WHO) factsheet states that globally 3 billion people cook using polluting open fires or simple stoves fuelled by kerosene, biomass (wood, animal dung and crop waste) and coal.

Annually, close to 4 million people die prematurely from illness attributable to household air pollution from improper cooking practices using polluting stoves paired with solid fuels and kerosene. Household indoor air pollution causes non-communicable diseases including stroke, ischemic heart disease, chronic 
obstructive pulmonary disease (COPD) and lung cancer. About half of deaths, due to pneumonia among children, less than 5 years of age are caused by particulate matter (soot) inhaled from household air pollution (4).

\section{SOURCES OF EXPOSURE - AIR POLLUTION}

The human activities contributes maximum to air pollution through various activities see figure-3 \&4 such as industrialization, world wars, power-producing stations, combustion engines, automobiles, missiles and nuclear testing's \& space activities. The transportation sector is responsible for about $55 \%$ of NOx total emissions inventory in the U.S., Less than $10 \%$ of VOCs emissions in the U.S., Less than 10\% of PM2.5 and PM10 emissions in the U.S. (5) Other notable human activities include agricultural works, gas stations, fuel tanks heaters, and cleaning procedures. The natural cause of air pollution such as volcanic and soil eruptions, sand storms and forest fires (Amazon forest fire, Brazil) also occurs now more frequently due to climatic changes and other factors.

The prime sources of air pollution are automobile emissions, oil refineries, emission of pollutants from power stations, petrochemicals industries, the chemical and fertilizer industries, metallurgical and other industrial plants, municipal incineration, agricultural crop burning. Indoor sources are domestic burning of biomass fuel for cooking; cleaning activities, dry cleaners, printing shops, and petrol stations. The moving sources such as automobiles, cars, railways, airways, and other types of vehicles are able to spread the pollution to a large area due to movement.

The natural sources of air pollution are mainly forest fire, volcanic erosion, dust storms etc. Air pollution is determined by the presence of pollutants in the air through automatic analyzers as well as manual techniques. Air pollutants are of various types such as, hydrocarbons, CO, CO2, NO, NO2, SO3, etc. Air pollution also influence the quality of soil and water bodies through rainfall (acid rain), pollutant accumulated in clouds falling into water and soil environments.

The quality and composition of soil is also changing due to acid precipitation $\&$ affecting plants, species, and water quality. Soil acidification, help in movement of metals to the water table in deep layers. Several metals are toxic to human and other life forms if ingested in larger amounts. Pollution also originates from radioactive and nuclear activities and through handling or disposal of radioactive sewage contaminating surface water bodies and, being noxious to the environment, plants, animals, and humans. Radioactive substances such as radium and uranium concentrate in the bones etc and can cause hematopoietic and other forms cancers. Air pollution is the major cause of disability adjusted life years lost (DALYs). Environmental pollution is said to occur when there are changes detrimental (physical, chemical, or biological constituents of the environment) to living beings (air masses, temperature, climate, etc.) are produced. Air pollution is due to increasing levels above normal or by introducing harmful toxic substances in atmosphere. Pollutants can be biodegradable or non biodegradable and of natural origin or anthropogenic, moreover, their origin can be a unique source (point source) or various sources. Aerosol compounds have a greater toxicity than gaseous compounds due to their tiny size (solid or liquid) in the 
atmosphere; they have a greater penetration capacity. Gaseous compounds are able to damage lungs and can even enter the blood stream by diffusing through alveoli, leading to the premature deaths of millions of people yearly.

\section{CLIMATE- POLLUTION- DISEASES-COVID-19}

Air pollution is closely related and responsible too for the global climatic changes. Pollutants present in atmosphere like black carbon, methane, troposphere-ozone, and aerosols affect the amount and quality of sunlight falling on earth. Due to these interactions, the temperature of the Earth is increasing every year, resulting in the melting of ice, icebergs, and glaciers raising sea levels. Climate and weather can affect the duration, timing, and intensity of outbreaks as well as may be related to progression of few epidemic $\&$ pandemic.

\section{Exposure to air pollution will increase the risk of diseases of the respiratory system - and the} COVID-19 is mainly a disease of the respiratory system -we are increasing the susceptibility, the vulnerability of people who are exposed to air pollution. AIR POLLUTANTS cause damage to lungs and other organs, increasing the risk of chronic respiratory diseases: lung cancer, obstructive chronic pulmonary diseases, asthma, pneumonia, and others. The very small particles can reach the bloodstream, affecting our cardiovascular system and other organs. In the case of the patients with COVID-19, patients more at severe risk of developing illness are those with underlying conditions like high blood pressure or heart diseases or respiratory diseases. Air pollution might exacerbate those diseases and make the patients, the population, more vulnerable to the disease, plus to the severity of developing a more serious illness (6). In a study done by Yan Cui 1, Zuo-Feng Zhang, John Froines, Jinkou Zhao, Hua Wang, Shun-Zhang Yu, Roger Detels titled Air pollution and case fatality of SARS in the People's Republic of China: published on 20november 2003, an ecologic study they found that air pollution was associated with increased risk of dying from SARS. This study demonstrated a positive association between levels of air pollution and SARS case fatality in Chinese population by analyzing SARS data and air pollution indices (7). Another study done by HeLia1Xiao-LongXub1Da-WeiDaic1Zhen-YuHuangc1ZhuangMaaYanJunGuan, titled Air pollution and temperature are associated with increased COVID-19 incidence: A time series study published on International Journal of Infectious Diseases, Volume 97, August 2020, Pages 278282 they found that air pollutants especially NO2 and PM2.5 increase the susceptibility of infection and mortality from COVID-19. The study also found air pollution associated with COVID-19 transmission. The poor communities using biomass fuel are more susceptible to be exposed to indoor air pollution $\&$ at more risk of becoming severely ill from COVID-19 infections. These studies illustrated impacts and importance of air quality toward public health protection and prevention to the spread of epidemics. In fact more research and evidence is required with elimination of bias and confounders like age, sex and pre-existing medical conditions along with prolonged exposure to NO2, PM2.5, and other air pollutants to confirm the association and detrimental effects of air pollution on mortalities from COVID-19. One important fact noted in India is that due to complete lockdown 2020, started on March 25 ending on $31^{\text {st }}$ may the air pollution reduced to a greater extent and covid-19 mortality-morbidity was also less. In 
a study done by SwadesPal, PriyankaDas, IndrajitMandal, RajeshSard, SusantaMahato, Kim-Anh Nguyen,Yuei AnLiou, SwapanTalukdar, SandiptaDebanshi, Tamal Kanti Sah, they found that there was reduction of LST by $4.02{ }^{\circ} \mathrm{C}$, PM10 level from 102 to $18 \mu \mathrm{g} / \mathrm{m} 3$, and AHF from 116 to $40 \mathrm{~W} / \mathrm{m} 2$ during lockdown period. AQI level was improved from poor to very poor state to moderate to satisfactory state (8). The countries like India can have a strategy of lockdown for controlling pollution for the benefit of public health.

\section{AIR POLLUTANTS}

As per WHO there are six major air pollutants i.e. particle pollution, ground-level ozone, carbon monoxide, sulfur oxides, nitrogen oxides, and lead. Air pollution have a negative impact on all components of the environment, including groundwater, soil, and air. The present day's acid rain, global warming, the greenhouse effect, and climatic changes have a negative ecological impact on air pollution. The penetrability and reach to various locations of human body depends upon size of PM (see table1). Another classification divide pollutant into primary and secondary (primary pollutant - emitted directly from a source, secondary pollutant is not directly emitted but forms when other pollutants (primary pollutants) react with themselves in the atmosphere) see table-2. These particulate matters are of various morphology-see figurel \& 2, 5

TABLE 1 | Penetrability of particulate matters (PM) according to particle size

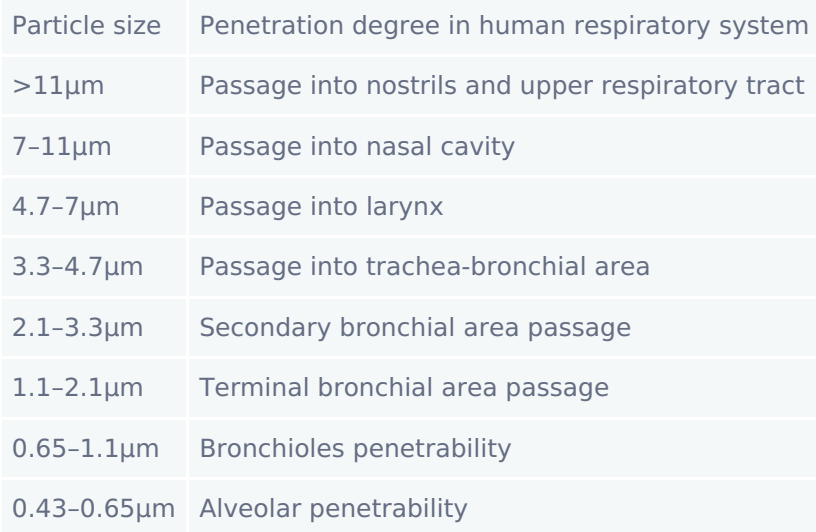

\section{Table2- Primary and secondary air pollutants}

\begin{tabular}{l|l|l|} 
Primary air pollutants & Secondary air pollutants \\
\hline Particles & Gases & Gases \\
\hline $\mathrm{PM}_{10}$ & $\mathrm{NO}$ & $\mathrm{O}_{3}$ \\
\hline $\mathrm{PM}_{2.5}$ & $\mathrm{SO}_{2}$ & $\mathrm{NO}_{2}$ \\
\hline $\mathrm{PM} 1$ & VOCs & \\
\hline
\end{tabular}

The composition of PM10 and PM2.5 can be organic (polycyclic aromatic hydrocarbons, dioxins, benzene, 1-3 butadiene's) or inorganic (carbon, chlorides, nitrates, sulfates, metals). Particulate Matter (PM) is divided into four groups according to type and size see-(Table $\mathbf{3}$ ).

Table 3- Particulate Matter (PM) divided into four groups according to type and size 


\begin{tabular}{|c|c|}
\hline Type & $\begin{array}{l}\text { Example - size PM diameter } \\
{[\mu \mathrm{m}]}\end{array}$ \\
\hline Particulate contaminants & $\begin{array}{l}\text { Smog } 0.01-1 \\
\text { Soot } 0.01-0.8 \\
\text { Tobacco smoke } 0.01-1 \\
\text { Fly ash } 1-100 \\
\text { Cement Dust } 8-100\end{array}$ \\
\hline Biological Contaminants & $\begin{array}{l}\text { Bacteria and } \\
\text { bacterial spores } \\
0.7-10 \\
\text { Viruses } 0.01-1 \\
\text { Fungi and molds 2-12 } \\
\text { Allergens (dogs, } \\
\text { cats, pollen, } \\
\text { household dust) } \\
0.1-100\end{array}$ \\
\hline Dust & $\begin{array}{l}\text { Atmospheric dust } 0.01-1 \\
\text { Heavy dust } 100-1000 \\
\text { Settling dust } 1-100\end{array}$ \\
\hline Gases & $\begin{array}{l}\text { Different gaseous } \\
\text { contaminants } \\
0.0001-0.01\end{array}$ \\
\hline
\end{tabular}

The half-lives of PM10 and PM2.5 particles in the atmosphere is prolonged due to their small size permitting long-lasting suspension in the atmosphere and transfer-spread to distant destinations. The fine particles are the main cause of the mist/fog/smog formation in atmosphere of polluted city and during lockdown in India due to reduction in pollution a range of Himalayas were visible from some parts of India which was not visible before lockdown. In a study done by ProfileXiao Wu, ProfileRachel C. Nethery, M. Benjamin Sabath, Danielle Braun, Francesca Dominici they found that a little rise in long-term exposure to PM2.5 leads to a large increase in COVID-19 death rate, with the magnitude of increase 20 times that observed for PM2.5 and all-cause mortality (9).

Ozone Impact on health Ozone (O3) is a gas formed from oxygen with high voltage electric current, a strong oxidant, 52\% stronger than chlorine and capable of oxidizing several living and non-living objects. Usually present in troposphere and stratosphere of atmosphere it can travel to distant areas moving with air masses. In high level it is harmful for cultures, forests, and vegetation as it is reducing carbon assimilation. It also disturbs homeostasis of ecosystem due to its oxidative capacity and reactions. Ozone can cause DNA damage in epidermal keratinocytes and leads to impaired cellular function. Ozone have low water-solubility hence inhaled ozone has the capacity to penetrate deeply into the lungs. Toxic level of ozone can cause biochemical, morphologic, functional, and immunological disorders due to oxidative stress and reactions. Ozone constricts muscles in the airways, trapping air in the alveoli leading to wheezing and shortness of breath. Depending on the level and amount-duration of exposure, ozone can cause coughing and sore or scratchy throat, making it more difficult to breathe and cause pain when taking a deep breath. It also inflames and damages the airways making the lungs more susceptible to infection. Ozone aggravates lung diseases such as asthma, emphysema, and chronic bronchitis increasing 
the frequency of asthma attacks (10). Hence covid-19 mortality and morbidity can be increased by toxic levels of ozone in atmosphere. Here I would like to mention different layers of atmosphere for better understanding. The atmosphere can be divided into layers based on its temperature. These layers are the troposphere (lowest), the stratosphere, the mesosphere and the thermosphere. A further region, beginning about $500 \mathrm{~km}$ above the Earth's surface, is called the exosphere. The earth behaves like a huge magnet trapping electrons (negative charge) and protons (positive), concentrating them in two bands about 3,000 and 16,000 km above the globe - the Van Allen "radiation" belts. This outer region surrounding the earth, where charged particles spiral along the magnetic field lines, is called the magnetosphere (11).

Carbon Monoxide (CO) Carbon monoxide is produced by burning of fossil fuel and automobiles. Increased CO causes, headache, dizziness, weakness, nausea, vomiting, asphyxia and, loss of consciousness at toxic levels. The affinity of carbon monoxide to hemoglobin is much greater forming carboxy-haemoglobin and depriving tissues of oxygen supply. This results in hypoxia, ischemia, and cardiovascular disease. Carbon monoxide also affects the greenhouses gases that are tightly connected to global warming and climate which is biggest challenge of $21^{\text {st }}$ century. In the case of covid-19 mortality and morbidity can be increased by the higher level of CO pollution.

Nitrogen Oxide (NO2) Nitrogen oxide is emitted from automobile motor engines, an irritant of the respiratory system penetrating deep in the lung, inducing respiratory diseases, coughing, wheezing, dyspnoea, bronchospasm, and pulmonary edema when inhaled at high levels. In a study done by (12)titled NO2 levels as a contributing factor to COVID-19 deaths : The first empirical estimate of threshold values they found that the threshold value of $\mathrm{NO} 2$ beyond which the number of deaths in the presence of COVID-19 would increase is between $15.8 \mu \mathrm{g} / \mathrm{m} 3$ for Lyon, $21.8 \mu \mathrm{g} / \mathrm{m} 3$ for Marseille and $22.9 \mu \mathrm{g} / \mathrm{m} 3$ for Paris.

Sulfur Dioxide (SO2) Sulfur dioxide is a harmful gas released as a byproduct of fossil fuel consumption and industrial activities. It causes respiratory tract irritation, bronchitis, mucus production, and bronchospasm and bronchoconstrictions. Skin, eyes, and CVS is also affected. The popular acid rain is due to emission of sulfur dioxide affecting environment and living beings in multiple ways. The sources of sulfur dioxide emissions are electricity generation, industrial boilers, petroleum refining and metal processing. Diesel engines are major source, including old buses and trucks, locomotives, ships, and off-road diesel equipment. Sulfur dioxide causes a range of harmful effects on the lungs, such as wheezing, shortness of breath and chest tightness. Continued exposure at high levels increases respiratory symptoms and reduces the ability of the lungs to function. Short exposures to peak levels of SO2 in the air can make it difficult for people with asthma to breathe when they are active outdoors. Increased risk of hospital admissions or emergency room visits, especially among children, older adults and people with asthma can be found especially in covid-19 patients hypothesized by the author, where air pollution is having higher levels of sulfur dioxide.

Lead is a heavy metal used in industrial plants and emitted from engines, batteries, radiators, waste incinerators, and waste waters. Lead can be inhaled, ingested, absorbed cutaneous, and transferred 
through placenta. Lead in high level can affect the central nervous system, accumulates in the blood, soft tissue, liver, lung, bones, and cardiovascular, nervous, and reproductive systems. It causes loss of concentration and memory, as well as muscle and joint pain. Since it is neurotoxic it can cause learning disabilities, impairment of memory, hyperactivity, and even mental retardation.

Polycyclic Aromatic Hydrocarbons (PAHs) PAH compounds, such as benzopyrene, acenaphthylene, anthracene, and fluoranthene are recognized as toxic, mutagenic, and carcinogenic substances. They are an important risk factor for lung cancer and used for a variety of purposes.

Volatile Organic Compounds (VOCs) Volatile organic compounds (VOCs), such as toluene, benzene, ethyl benzene, and xylene (90), are associated with cancer in humans. In a study (13)titled Diagnosis of COVID-19 by analysis of breath with gas chromatography-ion mobility spectrometry - a feasibility study they found that patients with COVID-19 can be rapidly distinguished from patients with other conditions at first healthcare contact by utilizing VOCs. The identity of the marker compounds is consistent with COVID19 derangement of breath-biochemistry by ketosis, gastrointestinal effects, and inflammatory processes.

Dioxins originate from natural and industrial processes, such as forest fires and volcanic eruptions. They particularly accumulate in foods such as meat and dairy products, fish and shellfish, and especially in the adipose tissue. More than $90 \%$ of human exposure is through food, mainly meat and dairy products, fish and shellfish. Many government authorities have programmes in place to monitor the food supply. Dioxins can cause reproductive and developmental problems, damage the immune system, interfere with hormones and also cause cancer. Due to the presence everywhere of dioxins, all people have background exposure, which is not expected to affect human health (14).

\section{EFFECT OF AIR POLLUTION ON HEALTH}

The effects of air pollution largely depend upon duration and levels of exposure. Vulnerable sections of population are old people, children, and people with diabetes mellitus and predisposing heart or lung disease, especially asthma $\&$ COPD. The short term exposure effects are usually temporary if exposed to lower concentrations ranging from simple discomfort, such as irritation of the eyes, nose, skin, throat, wheezing, coughing and chest tightness, and breathing difficulties, to exacerbations of asthma, pneumonia, bronchitis, and lung and heart problems. Headaches, nausea, and dizziness vomiting may occur. The long-term exposure to the pollutants can cause cancer and deaths. The long-term effects with low concentration exposures are chronic, lasting for years or the whole life leading to morbidity and death. Long-term effects are found in people with a predisposing disease state exposed to pollutant on regular basis. The pollution from traffic, industrial air pollution, and combustion of fuels are the major factors for COPD, CVS, and CNS risk.

\section{ENVIRONMENTAL IMPACT OF AIR POLLUTION}

Air pollution is harming not only human health but also the environment, environmental effects are in the form of acid rain is wet (rain, fog, snow) or dry (particulates and gas) precipitation containing toxic amounts of nitric and sulfuric acids. Acid rains acidify the water and soil environments, damage trees and 
plantations, and even damage buildings and outdoor sculptures, constructions, and statues. London smog and delhi smog are excellent examles to know the hazards of air pollution. The Global climate change is a burning issue of $21^{\text {st }}$ century globally that concerns mankind. The anthropogenic activities have destroyed this protecting temperature effect (greenhouse effect) by producing large amounts of pollutant gases, and global warming is increasing, with detrimental effects on human health, animals, forests, wildlife, agriculture, and the water environment. The wildlife is also affected on earth and sea by toxic pollutants coming from the air, soil, or the water ecosystem. Reproductive and birth defects have been reported.

\section{DISCUSSION \& CONCLUSION}

WHO Global Conference on Air Pollution and Health(2018), the WHO's General Director, Dr. Tedros AdhanomGhebreyesus, said air pollution a public health emergency (15). International collaboration in research, development, administration, policy, monitoring, and politics is vital for effective pollution control. Legislation concerning reduction of air pollution must be aligned and updated, and policy makers should propose the design of a powerful tool of environmental and health protection. The globe should focus on ways to prevent environmental pollution and climatic changes in order to save lives and reduce global burden of disease.

\section{'Declarations':}

-This paper has not been previously published and is not currently under consideration by another journal. The document is Microsoft word with English (United States) language \& 4927 words Total.

- Ethics approval and consent to participate: Not applicable. This study has not involved any human or animals in real or for experiments.

-Consent for publication: Not applicable

-Availability of data and materials: The data \& materials for study are available as reference.

-Conflicts of Interest/ Competing Interest: There are no conflicts / competing of interest

- Funding-Self sponsored. No aid taken from individual or agency etc.

- Authors' contributions: The whole work is solely done by the Author - Dr Piyush Kumar, M.B.B.S. - Sri Krishna Medical College, EMOC- General Medical Officer- Bihar Health Services- Government of Bihar, India.

- Acknowledgements- I am thankful to Advocate Anupama my wife for cooperation.

- Author information: The author is currently working as general medical officer for the government of Bihar.

\section{-Financial Support \& sponsorship: Nil}

\section{REFERENCES}

1. WHO, Air Pollution, Available online at: https://www.who.int/health-topics/air-pollution\#tab=tab_1 (Accessed on 08/06/2021).

2. Bell ML, Davis DL, Fletcher T. A retrospective assessment of mortality from the London smog episode of 
1952: the role of influenza and pollution. Environ Health Perspect. 2004 Jan;112(1):6-8. doi: 10.1289/ehp.6539. PMID: 14698923; PMCID: PMC1241789.

3. Dockery DW, Pope CA 3rd, Xu X, Spengler JD, Ware JH, Fay ME, Ferris BG Jr, Speizer FE. An association between air pollution and mortality in six U.S. cities. N Engl J Med. 1993 Dec 9;329(24):1753-9. doi: 10.1056/NEJM199312093292401. PMID: 8179653.

4. WHO, Air Pollution, Available online at: https://www.who.int/news-room/fact-sheets/detail/household-airpollution-and-health, (Accessed on 09/06/2021).

5. U.S environmental protection agency, available online at- https://www.epa.gov/transportation-airpollution-and-climate-change/smog-soot-and-local-air-pollution, (Accessed on 09/06/2021)

6. WHO, Dr Maria Neira, Available online at: https://www.who.int/emergencies/diseases/novelcoronavirus-2019/media-resources/science-in-5/episode-9---air-pollution-covid-19, (Accessed on 09/06/2021).

7. Cui, Y., Zhang, ZF., Froines, J. et al. Air pollution and case fatality of SARS in the People's Republic of China: an ecologic study. Environ Health 2, 15 (2003). https://doi.org/10.1186/1476-069X-2-15

8. KantiSahaa, SwadesPalaPriyankaDasaIndrajitMandalaRajeshSardaaSusantaMahatoaKimAnhNguyenbYuei-AnLioubSwapanTalukdaraSandiptaDebanshiaTamal, Effects of lockdown due to COVID-19 outbreak on air quality and anthropogenic heat in an industrial belt of India, available athttps://www.sciencedirect.com/science/article/pii/S0959652621008945(visited on-10/06/2021) 9. Air pollution and COVID-19 mortality in the United States: Strengths and limitations of an ecological regression analysis. Wu1, R. C. Nethery1,M. B. Sabath1, Braun1,2 andF. Dominici1,Science Advances 04 Nov 2020:Vol. 6, no. 45, eabd4049,DOI: 10.1126/sciadv.abd4049

10. Health Effects of Ozone Pollution, United States Environmental Protection Agency, available athttps://www.epa.gov/ground-level-ozone-pollution/health-effects-ozone-pollution(visited on-10/06/2021). 11. Layers of the atmosphere, available at- https://niwa.co.nz/education-andtraining/schools/students/layers(visited-10/06/21)

12. Mele M, Magazzino C, Schneider N, Strezov V. NO2 levels as a contributing factor to COVID-19 deaths: The first empirical estimate of threshold values. Environ Res. 2021 Mar;194:110663. doi: 10.1016/j.envres.2020.110663. Epub 2021 Jan 5. PMID: 33417906; PMCID: PMC7783466 13. available at - https://www.thelancet.com/journals/eclinm/article/PIIS2589-5370(20)30353-9/fulltext 14. WHO, Dioxins and their effects on human health, available at- https://www.who.int/news-room/factsheets/detail/dioxins-and-their-effects-on-human-health 15. available at- https://www.theguardian.com/environment/2018/oct/27/air-pollution-is-the-new-tobaccowarns-who-head

Figure-1- Particulate Matter-Morphology- Chitra and Nagendra, (2012); Valson et al., (2015) 

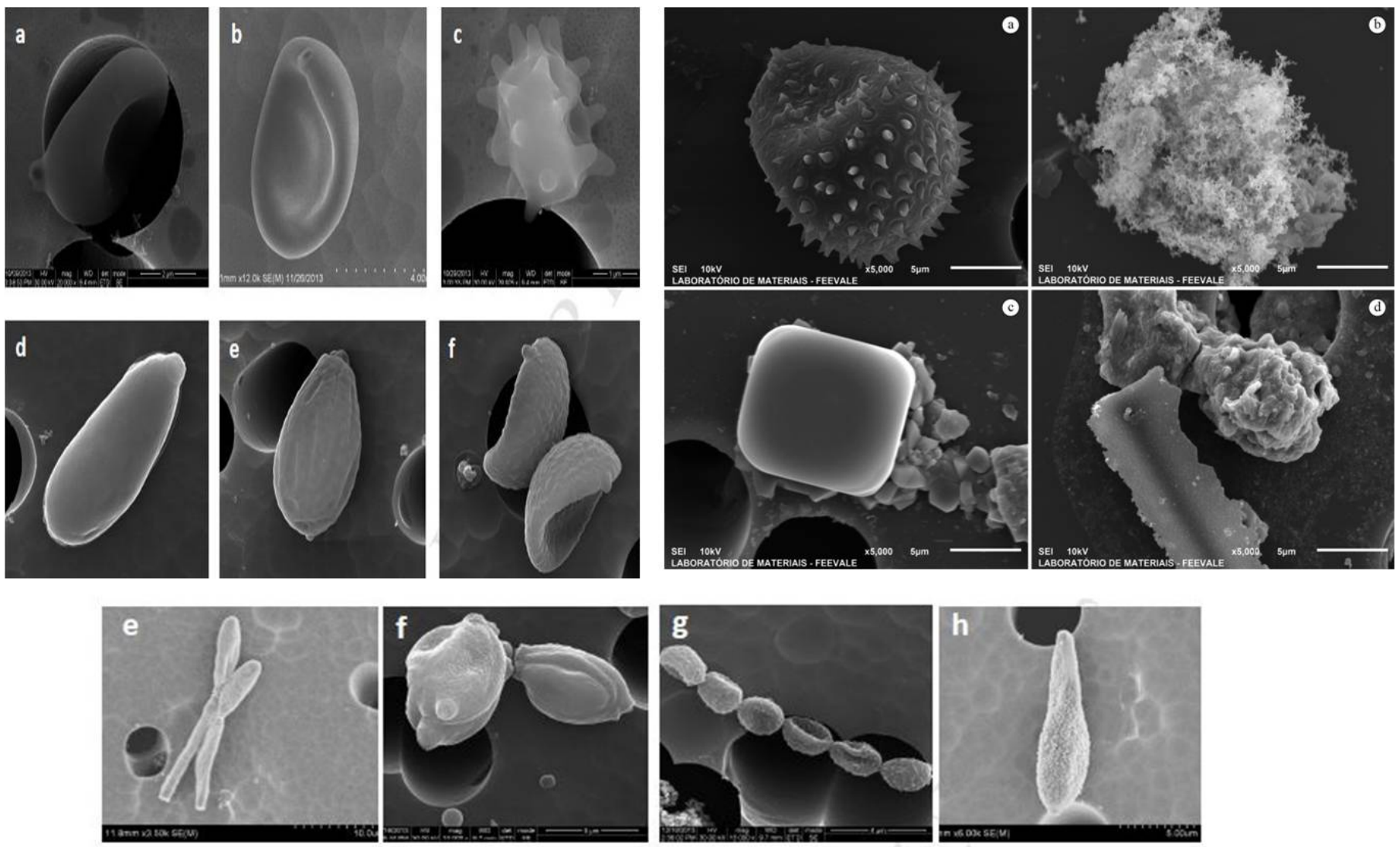

Figure-1- Particulate Matter-Morphology- Chitra and Nagendra, (2012); Valson et al., (2015)

Figure-2- Atmospheric particle size 


\section{Atmospheric particle size}

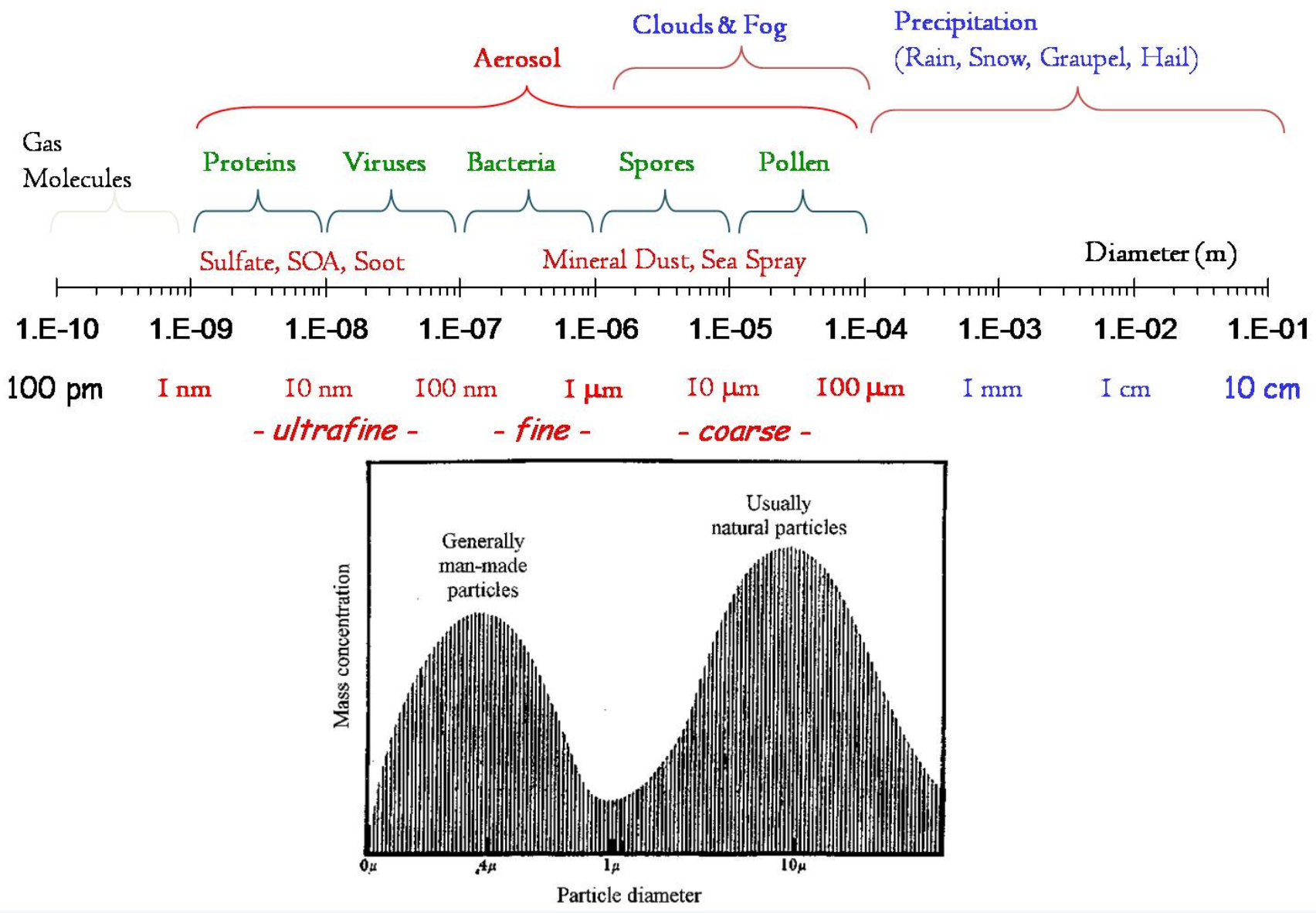

Figure-2- Atmospheric particle size

Figure-3-sources of PM and air pollution 

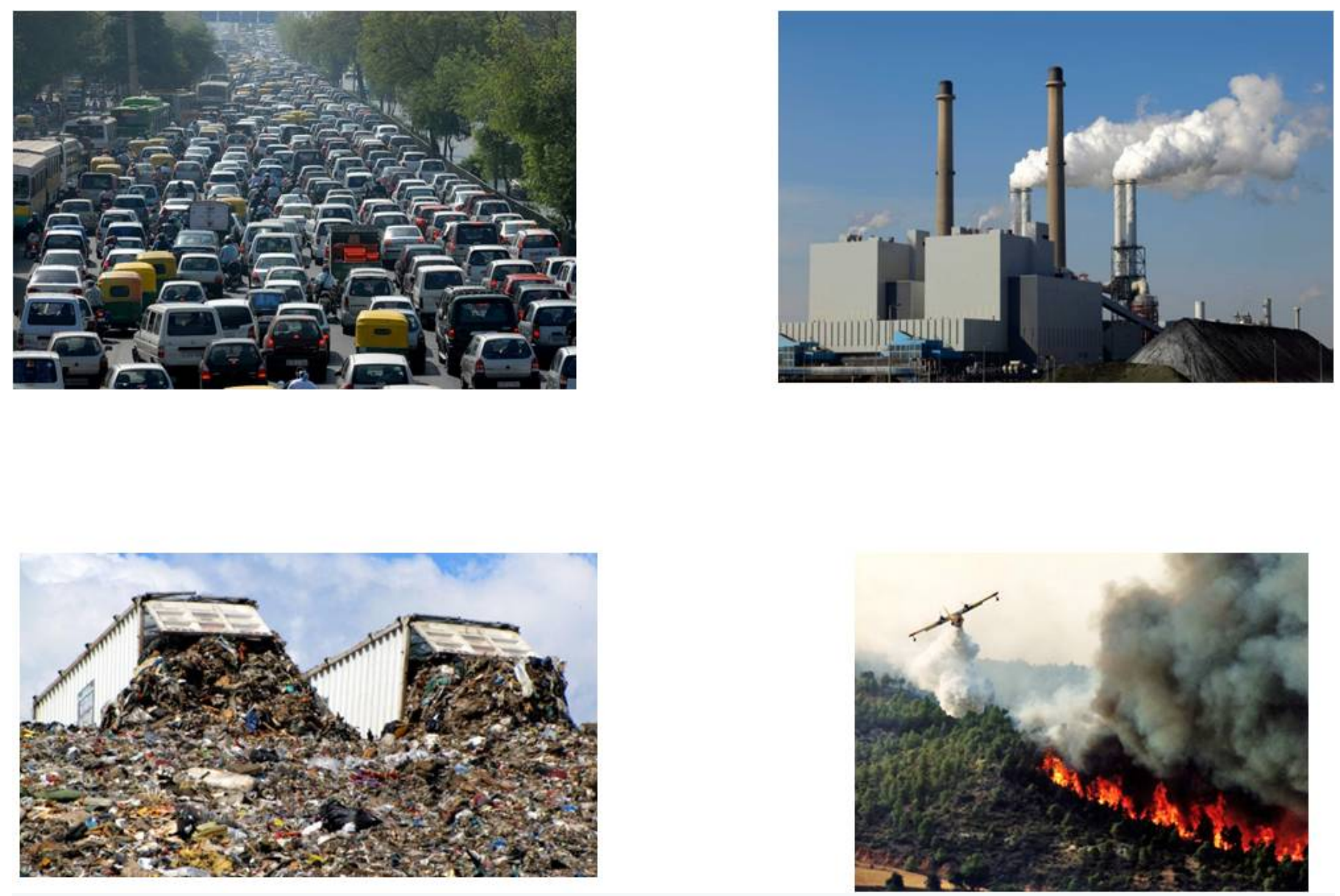

Figure-3-sources of PM and air pollution

Figure-4-effect of air pollution

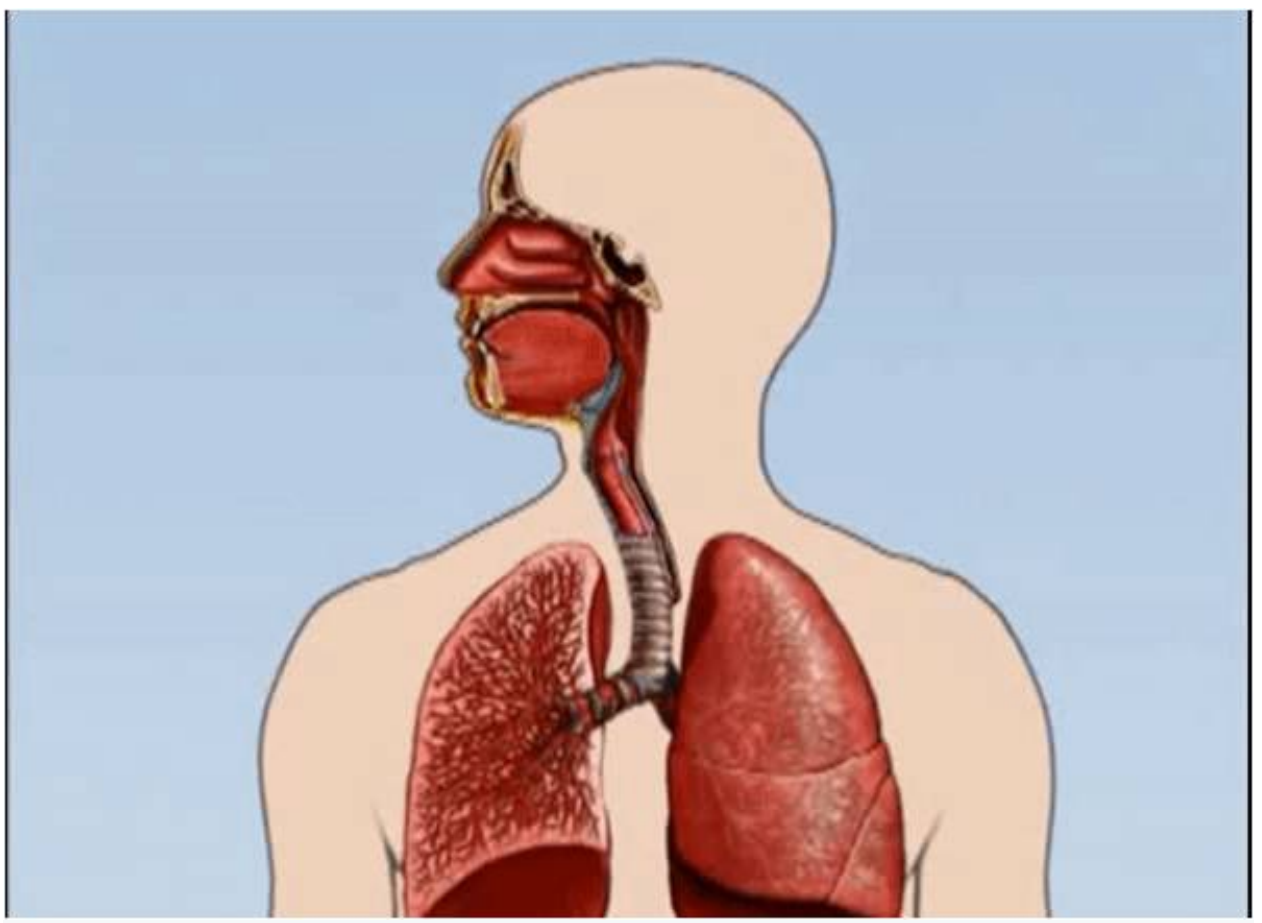

Figure-4-effect of air pollution 
Figure-5- particle size and its fate

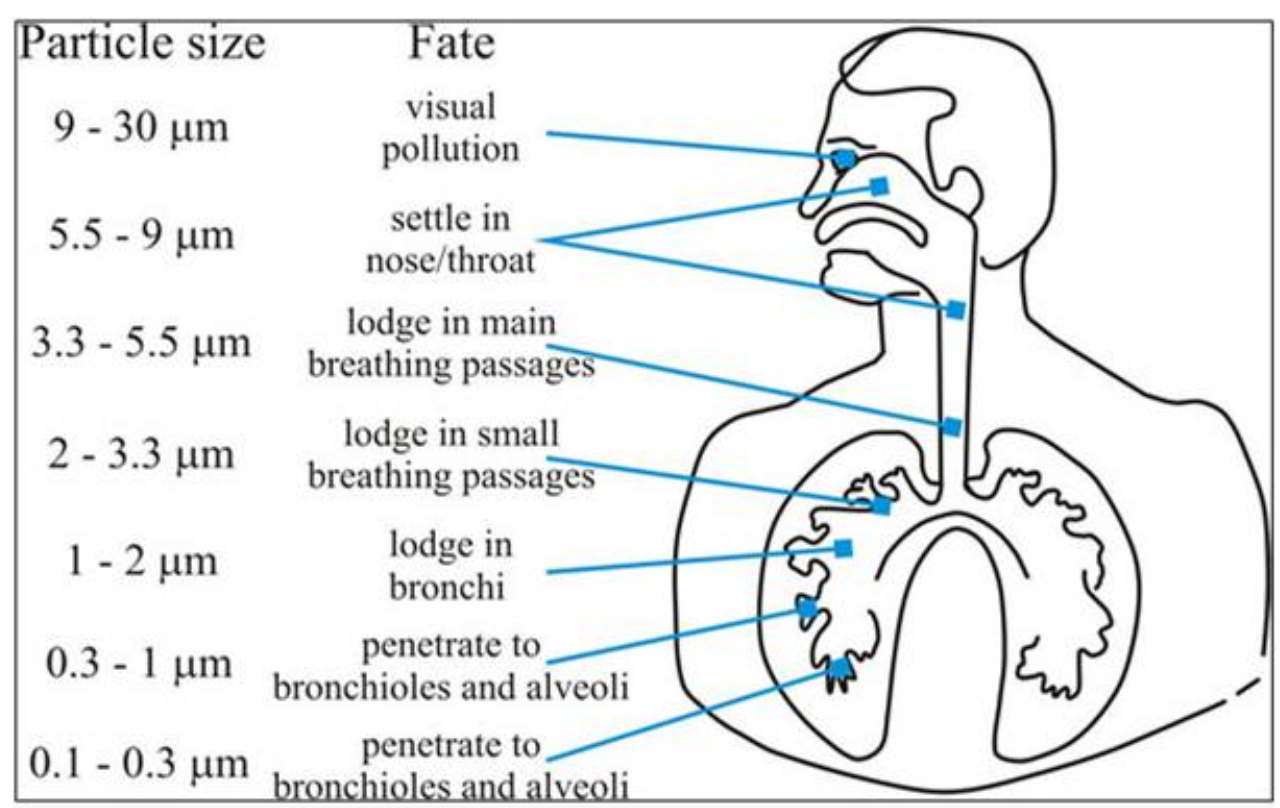

Figure-5- particle size and its fate

THANK YOU 